\title{
Biological Maturation and Its Impact on Overhand Shot Technique Among Young Badminton Players
}

Alif Syamim Syazwan Ramli, Tengku Fadilah Tengku Kamalden, Raihana Sharir, Hazreen Haizi Harith, Marsyita Hanafi

To Link this Article: http://dx.doi.org/10.6007/IJARBSS/v10-i12/8346

DOI:10.6007/IJARBSS/v10-i12/8346

Received: 04 November 2020, Revised: 29 November 2020, Accepted: 15 December 2020

Published Online: 24 December 2020

In-Text Citation: (Ramli et al., 2020)

To Cite this Article: Ramli, A. S. S., Kamalden, T. F. T., Sharir, R., Harith, H. H., \& Hanafi, M. (2020). Biological Maturation and Its Impact on Overhand Shot Technique Among Young Badminton Players. International Journal of Academic Research in Business and Social Sciences, 10(12), 487-496.

Copyright: (C) 2020 The Author(s)

Published by Human Resource Management Academic Research Society (www.hrmars.com)

This article is published under the Creative Commons Attribution (CC BY 4.0) license. Anyone may reproduce, distribute, translate and create derivative works of this article (for both commercial and non-commercial purposes), subject to full attribution to the original publication and authors. The full terms of this license may be seen

at: http://creativecommons.org/licences/by/4.0/legalcode

Vol. 10, No. 12, 2020, Pg. 487 - 496

Full Terms \& Conditions of access and use can be found at http://hrmars.com/index.php/pages/detail/publication-ethics 


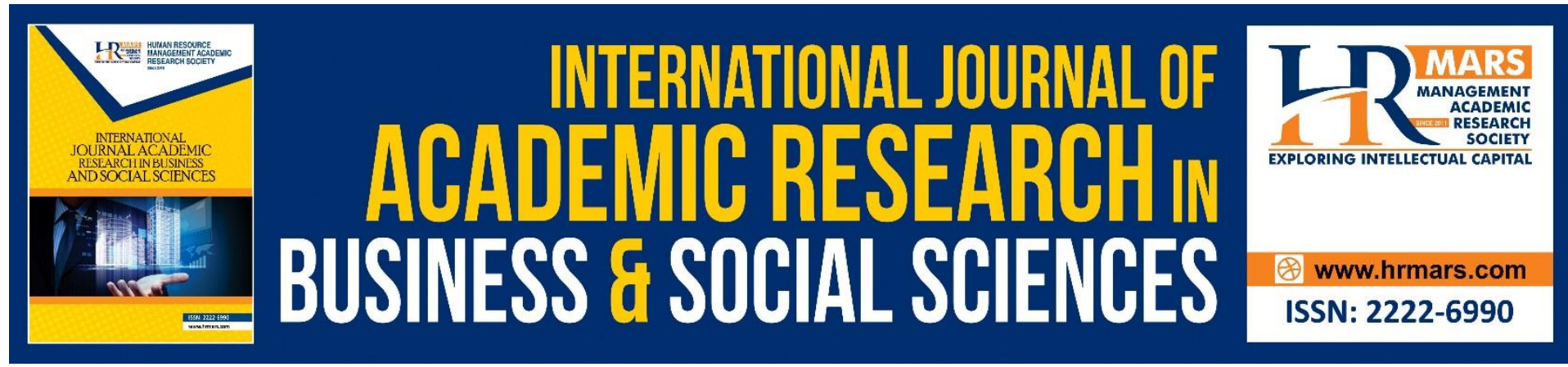

\title{
Biological Maturation and Its Impact on Overhand Shot Technique Among Young Badminton Players
}

\author{
Alif Syamim Syazwan Ramli ${ }^{1}$, Tengku Fadilah Tengku \\ Kamalden ${ }^{1}$, Raihana Sharir², Hazreen Haizi Harith ${ }^{3}$, Marsyita \\ Hanafi ${ }^{3}$ \\ ${ }^{1}$ Faculty of Educational Studies, Universiti Putra Malaysia, Malaysia, ${ }^{2}$ Faculty of Sport \\ Science and Recreation, Universiti Teknologi MARA, Malaysia, ${ }^{3}$ Faculty of Engineering, \\ Universiti Putra Malaysia, Malaysia. \\ Email: alifsyamimsyazwan@yahoo.com, tengku@upm.edu.my, raihanasharir@uitm.edu.my, \\ hazreen@upm.edu.my,marsyita@upm.edu.my
}

\begin{abstract}
Overhand shot technique is the most prevalent technique in badminton and is often emphasized by coaches during training. However an overemphasis on a particular technique might have a different impact on young badminton players who is undergoing puberty period. Previous studies had mentioned little on the impact of biological maturation in influencing sports technique. The aim of this paper is to review the overhand shot technique in badminton among young badminton players in the context of biological maturation impact. This includes the relationship between biological maturation, physical growth and overhand shot technique. The existing literatures have highlighted the potential impact of biological maturation on sport technique, particularly badminton overhand shot among young players. More in depth studies are needed on the impact of biological maturation in young badminton players on technical execution of the overhand shot for better understanding on this matter. Such work can be useful in ensuring an excellent shot technical proficiency and hence increase chance of winning the match in badminton among young badminton players.
\end{abstract}

Keywords: Biological Maturation, Badminton, Shot Technique, Young Players

\section{Introduction}

Badminton is among the most popular and widely-played sports in the world, with estimated around 200 million people play this sport worldwide according to the Badminton World Federation (BWF) (Phomsoupha \& Laffaye, 2015). Earlier at international scale, European countries such as Denmark, England, and Germany conquered the badminton. However, in the past few decades, the dominance seemed to have shifted to Asian countries, most notably, China, Indonesia, Japan, Malaysia, and South Korea. All of whom seem to produce a list of world class players. The popularity of this sport has led to focused attention on performance improvement and detailed study and understanding of all aspects including technical skills in badminton. What makes badminton exciting and interesting is attributed by its fast playing rhythm and constant interaction by players between offensive and defensive 
shots throughout the match, constantly struggle throughout the game (El-Gizawy, 2015). Moreover, current 21-point system when compared to the old system (15-point in male, 11point in female) has displayed more aggressive strategy (greater intensity, faster speed of play and longer rally lengths) (Abian et al., 2014; Phomsoupha \& Laffaye, 2015) thus these put emphasis on technical skill effectiveness of badminton shot to meet the demands of the current game (Ming et al., 2008). Performing various shots in badminton requires elegant and delicate techniques, which must be constructed and delivered through precise coordination and control (Glazier, 2017).

A literature search for articles was conducted in the databases such as PubMed, SienceDirect, Scopus and Web of Science. An additional search (including relevant grey literatures) was also done on the internet through ResearchGate and Google Scholar. The content was based on the literature review of past researches that are relevant with the key words such as biological maturation, maturation assessment, badminton, shot technique, young athletes, youth, biomechanics and biomechanical analysis of technique.

\section{Badminton: The Fastest Racquet Sport}

Badminton appears to be one of the fastest sports in the world, as players perform approximately 1 shot every 2 seconds with the shuttlecock often reaching velocities over $360 \mathrm{~km} / \mathrm{h}$ (Faude et al., 2007). According to official Guinness World Record, the fastest shuttlecock velocity in actual badminton tournament $(426 \mathrm{~km} / \mathrm{h})$ was made by Mads Pieler Kolding in year 2017 during a Badminton Premier League match playing for the Chennai Smashers, highlighting that badminton can be considered as the fastest racquet sport. In badminton, players are sequentially trading shots until a shot is not returned or is played out of the boundaries of the playing area to score a point. Since badminton is a dynamic sport with complicated skills, the nature of this sport requires players to master skills including effective badminton shot and proper footwork. Considering the way this sport is played, it tests the reactive ability of players where players have to react swiftly with very limited time. Combined with more offensive strategy in the current point system, players preferred attacking by playing more often offensive shots than defensive shots (Abian-Vicen et al., 2013; Phomsoupha \& Laffaye, 2015).

Shuttlecock velocity is a crucial performance factor, as it has been associated with skill levels (higher-level player produced higher shuttlecock velocity) (Phomsoupha \& Laffaye, 2014) and a major contributor to number of points in badminton match (Phomsoupha \& Laffaye, 2020). In badminton, technique is related to how to move and hit the shuttlecock. Badminton shot is a technique of hitting the shuttlecock. There are three types of situations during badminton gameplay which are offensive (attacking), neutral and defensive which are related to how high the shuttlecock is when it is being hit. These situations are represented in the illustration below (Figure 1). It is important to hit the shuttlecock early in terms of both height and closeness to the net as the player can be in offensive situations more often (more opportunities for offensive shots) and exert more pressure on opponent (shorter reaction time) (El-Gizawy, 2015; Pandey et al., 2019). Overhand shots could be regarded as the fundamental to play badminton and considered as important offensive shots (Grice, 2008; Brahms, 2010). These shots include smash, clear and drop. Smash shot is an aggressive overhand shot with a downward trajectory; Clear shot is an overhand shot with a flat or rising 
trajectory towards the back court area; and drop shot is a smooth overhand shot with a downward trajectory towards the front court area (Phomsoupha \& Laffaye, 2015).

When it comes to offensive shots, players focus on powerful overhand shot to produce high post-impact shuttlecock velocity with a flat or downward trajectory so that the opponent can be pressured effectively due to the minimal reaction time to intercept the incoming shuttlecock and wins a point (King et al., 2020). If a player is able to perform overhand shot that causes the shuttlecock to travel at a high velocity and give the opponent shorter reaction time to the shot, it would be expected that shot would be regarded as an effective weapon, commonly known as 'power stroke' (shot that results in the greatest shuttlecock velocity after impact (Zhu, 2013).

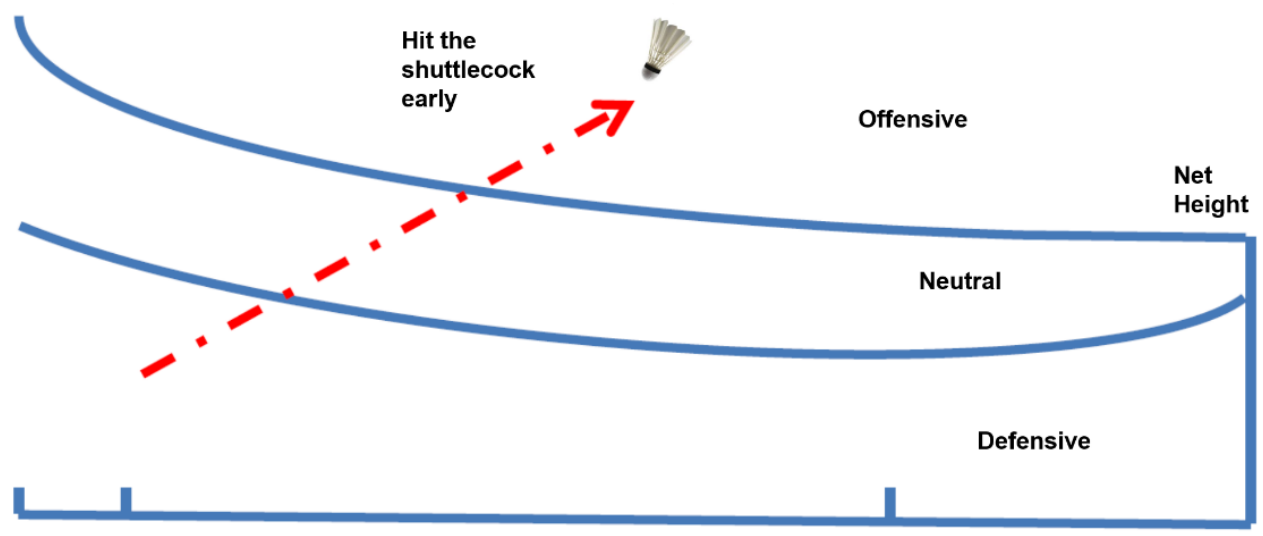

Figure 1: Situations in badminton gameplay.

\section{Young Athletes Grow Mature: An Overview of Biological Maturation}

Human transits from childhood to adulthood involves multi-dimensional developmental changes. World Health Organization (WHO) defines 'adolescents' as individuals with age range between 10 and 19 years old and 'young people' between 10 to 24 years old. Malina et al. (1982) set an upper limit for definition of young athletes at 18 years old, and have emphasized a critical period of adolescent phase of biological maturation about 9 through 16 years old. Puberty is a process of children growing and obtaining adult stature, typically occuring around 10 to 17 years old for girls and 11 to 17 years old for boys (Kail \& Cavanaugh, 2016). Puberty includes changes of the biological maturation that adolescents encounter. Biological maturation is a progression towards the biologically mature state or biological maturity, and in reference to an individual's biological age (BA) (Baxter-Jones, 1995; Malina, 2014). Biological maturation is a process and occurs in all bodily organs and systems. On the other side, biological maturity is a state and varies with the biological system considered (Malina, 2014). Biological maturation is a biological process where its timing and tempo vary among individuals (Malina, 2014). Timing refers to a point when specific milestones in maturation occur, while tempo refers to the rate at which the process of biological maturation advances. Due to individual timing and tempo in biological maturity, there is a large range in timing when individuals start and finish biological maturity and this is most apparent during adolescent development, typically occurring around ages 10-14 in females and 12-16 in males (also known as period of puberty) (Mirwald et al., 2002; Tanner, 1978).

As adolescents mature older, they physically grow up as well. Physical growth is defined as a quantitative increase in the size of a body parts or the body itself as a whole (Baxter-Jones, 
1995; Malina et al., 2014). Growth spurt is the term that is used to describe any period of accelerated physical development. In males, the peak growth spurts of height, weight, and muscle seem to happen simultaneously in adolescent males, however in females, the peak growth spurts happen sequentially in that order (Brown et al., 2017). Adolescent females reach peak height velocity (PHV) chronologically earlier at lower velocity while for adolescent males, they reach PHV chronologically later at greater velocity (Tanner, 1978). Height and weight are the body dimensions most commonly used for growth monitoring. As the adolescent grow older, they are expected to grow taller and heavier. Around 10 years of age in girls and 12 years of age in boys, the rate of growth in height accelerates (growth spurt) (Malina et al., 2014). The rate of growth increases until it reaches a peak (PHV), the maximum rate of growth in height during the spurt. The rate of growth in height gradually decreases and eventually reaches zero (Mirwald et al, 2002; Tanner, 1978).

Earlier maturing males are generally taller, heavier, have higher mass-to-height ratios and broader shoulders than later maturing males, whereas earlier maturing females have greater hip breadth, relatively shorter legs and greater body fatness than later maturing females (Armstrong, 2013). Between height and weight, the growth spurt in body weight begins rather later compared to that in height. Different from height, weight increases continuously until age reaches twenties. Body weight consists of a composite of bodily tissues, however often that it is regarded based on its lean (fat-free) and fat components. In that sense, body weight is consisted of fat-free mass (FFM) and fat mass (FM). Major components of FFM include bone and skeletal muscle. Most other body dimensions and many major organs follow growth patterns similar to the pattern for height and weight (Malina, 2014).

\section{Role of Biological Maturation on Badminton Overhand Shot Technique among Young Players}

Technique is defined as the 'way of doing' and specifically in sport, can be defined as the way in which that sports skill is performed (Lees, 2002; Hughes \& Franks, 2008). When dealing with young athletes, executing efficient overhand shot technique can be more difficult and challenging, as one must consider developmental factors due to the biological maturation in young players. Such factors include the changes in body dimensions, chronological and biological age as well as biomechanical changes related to growth and development, which are likely to have an impact on technique (Glazier, 2017). As adolescents biologically mature, their hormonal phenomenon, anatomy and movement biomechanics are significantly changed, with young boys and girls undergoing meaningfully different maturational effects (Quatman et al., 2006). Past literatures have shown that lower extremity biomechanical characteristics were influenced by biological maturation factor (Sigward et al., 2011; Sigward et al., 2012; Glazier, 2017; Radnor et al., 2018). Due to the biological maturation, the increase in physical ability (strength, power, speed, etc.) becomes apparent in adolescent (Radnor et al., 2018) due to neural and muscular systems development.

Development of neural system occurs through myelination of axons, in which increase in myelination causes improved coordination, and this improved coordination results from faster motor unit recruitment and synchronization, as well as faster cycles of contractionrelaxation (Viru et al., 1999). For development of muscular system, previous research has shown that there is a significant improvement in muscle mass during puberty period, which is associated with increased hormonal production (Viru et al., 1999). Previous research 
suggested that the neuromuscular system changes during biological maturation include increases in tendon stiffness, muscle size, fascicle length, pennation angle, motor unit recruitment and pre-activation, and this may result in an improved stretch-shortening cycle (SSC) function (Radnor et al., 2018). SSC function is very important in increasing the efficiency of the force production in badminton overhand shot technique for the whip-like movement (Phomsoupha \& Laffaye, 2014; Mughal, 2019).

During biological maturation, adolescents experience rapid growth, where the long bones grow at rapid rate during puberty. This rapid growth leads to a notable increase in height for both genders. In badminton, players' anthropometry and motor performance seems to be the most crucial determinants of success in badminton match (Ismail et al., 1993; Lei et al., 1993). When height is being considered, this anthropometric variable appears to differentiate skill level between badminton players (Phomsoupha and Laffaye, 2015). Shot technique appears to be different across skill level, where highly-ranked badminton players showed better technique (efficient sequential joint action) that produces higher post-impact shuttlecock velocity compared to lowered-ranked players (Sorensen et al., 2011). However, this pubertal height increase also creates longer levers and potential increases in torque at the knee joint (Quatman et al., 2006). Higher center of mass resulted from the increased skeletal size and mass during adolescence period induces more difficult muscular control of the body.

Newell (1984) particularly highlighted the constraint of the moment of inertia (MOI) of limb and trunk segments during maturation period. $\mathrm{MOl}$ of a body segment expresses its tendency to resist angular acceleration, which is the product of its mass and the square of its distance from rotation axis, and several studies have shown racquet swing speed is highly correlated with the MOI (Kwan \& Rasmussen, 2011). Any increases in the MOI of body segments (longer and heavier body segments) need to be matched by demanding increases in torques produced about the active joints but the development of muscular strength typically lags behind increases in $\mathrm{MOI}$ of body segments, thus this can adversely affect patterns of coordination and control which leads to reduced technical proficiency i.e. overhand shot technique among young badminton players. This phenomenon was described later as "adolescent awkwardness" (Davies \& Rose, 2000). This may happen temporarily, and once they have undergone growth spurt period, the physical abilities (strength, mobility, etc.) is catching up hence developing not only good overhand shot technique but also necessary speed and force to hit the shuttlecock effectively (Jaworski \& Zak, 2016). One of few studies that focused on adolescent player in badminton sport skills is recent study of Jaworski \& Zak (2016). They highlighted the significant impact of biological maturation on sport skill in badminton, which in effect, should be significant as well when associated to technical proficiency in overhand shot technique execution.

\section{Future Perspectives}

Current trend in sport research has focused into exclusive young population (Glazier, 2017; Corso, 2018). Goals of the sport biomechanics are to enhance sport performance and prevent injury, and sport biomechanists often directed their efforts to optimise the biomechanical, or technique, components of sport performance (Hall, 2015). Considering the potential impact of biological maturation on shot technique in badminton, future work on this area is warranted. Glazier (2017) has highlighted that lack of coverage from the subdiscipline of sport 
biomechanics can be partly explain the reason why talent identification and development (TID) programmes may not be as impactful as intended to be. The absence of a biomechanics component from TID programmes could be a major shortcoming, as it appears that in many sports, one of the strongest indicators of 'talent' is perhaps the technical proficiency with which motor skills essential to those sports are performed (Glazier, 2017). Since one of the goals during talent development is to develop efficient and safe sport techniques, sport biomechanics subdiscipline could make a useful contribution in TID programmes. The development of technique model based on mechanically sound technique (the application of biomechanical principles) may be useful for the comparison and identification of effective and safe technique patterns in sport during talent identification and development (Glazier, 2017).

Due to the individual variability in timing and tempo of biological maturation, biological age (BA) is a better measure for individual comparisons as opposed to assessing them based on their chronological age (CA) (Malina et al., 2014).Nowadays, there are a number of different ways to assess biological maturation. To measure biological age, several methods existed. The maturity status and progression of children and adolescents are traditionally monitored in the skeleton (skeletal maturity) and secondary sex characteristics (sexual maturity). However, the limitations to this method include very invasive to the individuals' privacy, impractical, limiting due to time commitments and assessment time, as well as subjective because they depend on the person rating the stages. Considering all these limitations, somatic maturity method seems to be convenient and practical to be used. Practical use of somatic maturity assessment method makes the research that explores biological maturation impact on sport performance, including sport technique become more convenient. Cumming et al. (2017) and Malina et al. (2019) have highlighted the concept of bio-banding in sport which is the process of grouping athletes on the basis of attributes related to biological side of growth and maturation rather than chronological age, and emphasised that bio-banding work should be consider technical development as a part of the work in order to be more comprehensive.

\section{Conclusion}

Badminton is a highly demanding sport which involves overall functioning of the body and its responses. Considering crucial technical part of the overhand shot technique being the most prevalent technique in badminton and is often emphasized by coaches during training for the development of young badminton players, this warrants better attention. This consideration is based on the complex interaction between the information of human ontogeny and the awareness of individual differences in developmental characteristics among adolescents. Based on the existing researches, the impact of biological maturation on technical performance in badminton, that is overhand shot technique is established and should be highlighted. Moreover, research related to this technical performance in badminton sport among young players need to be further considered, as it is important that the overhand shot technique in badminton to be well understood in order to ensure an excellent shot technical proficiency and hence increase chance of winning the match in badminton among young badminton players.

\section{References}

Abian, P., Castanedo, A., Feng, X. Q., Sampedro, J., \& Abian-Vicen, J. (2014). Notational comparison of men's singles badminton matches between Olympic Games in Beijing and London. International Journal of Performance Analysis in Sport, 14, 42-53. 
Abian-Vicen, J., Castanedo, A., Abian, P., \& Sampedro, J. (2013). Temporal and notational comparison of badminton matches between men's singles and women's singles. International Journal of Performance Analysis in Sport, 13(2), 310-20.

Armstrong, N. (2013). Developing of the elite young athlete. JPASPEX (2013), 1(1), 1-8.

Baxter-Jones, A. D. G. (1995). Growth and development of young athletes: Should competition levels be age related? Sports Medicine, 20(2), 59-64.

Brahms, B. V. (2010). Badminton handbook (2nd edition). Auckland: Meyer and Meyer Sport.

Brown, K. A., Patel, D. R., \& Darmawan, D. (2017). Participation in sports in relation to adolescent growth and development. Translational Pediatric, 6(3), 150-159.

Corso, M. (2018). Developmental changes in the youth athlete: implications for movement, skills acquisition, performance and injuries. The Journal of the Canadian Chiropractic Association, 62(3), 150-160.

Davies, P. L., \& Rose, J. D. (2000). Motor skills of typically developing adolescent: Awkwardness or improvement? Physical \& Occupational Therapy in Pediatrics, 20(1).

El-Gizawy, H. H. (2015). Effect of visual training on accuracy of attack shots performance in badminton. Journal of Applied Sports Science, 5(4).

Faude, O., Meyer, T., Rosenberger, F., Fries, M., Huber, G., \& Kindermann, W. (2007). Physiological characteristics of badminton match play. European Journal of Applied Physiology, 100, 479-485.

Glazier, P. S. (2017). Could sports biomechanics provide the missing pieces to the talent identification and development puzzle? In Baker, J., Cobley, S., Schorer, J., \& Wattie, N. (Ed.). Routledge Handbook of Talent Identification and Development in Sport. Routledge.

Grice, T. (2008). Badminton: Steps to Success (2nd edition). Human Kinetics.

Hall, S.J. (2015). Basic biomechanics (7th edition). McGraw-Hill Education.

Hewett, T. E., Myer, G. D., \& Ford, K. R. (2004). Decrease in neuromuscular control about the knee with maturation in female athletes. Journal of Bone \& Joint Surgery, 86-A(8), 1601-1608.

Hughes, M., \& Franks, I.M. (2008). The essentials of performance analysis: An introduction. Routledge.

Ismail, M. S., Ang, B. S., Othman, C. N., Ahmad, A., \& Singh, R. (1993). Comparison of anthropometric variables and leg strength of volleyball, basketball and badminton players. Malaysian Journal of Medicine and Laboratory Sciences, 10(1), 26-30.

Jaworski, J., \& Zak, M. (2016). Identification of determinants of sport skill level in badminton players using the multiple regression. Human Movement, 17(1), 21-28.

Kail, R. V., \& Cavanaugh, J. C. (2016). Human development: A life-span view (7th edition). Cengage Learning.

King, M., Towler, H., Dillon, R., \& McErlain-Naylor, S. (2020). A correlational analysis of shuttlecock speed kinematic determinants in the badminton jump smash. Applied Sciences, 10(1248).

Kwan, M., \& Rasmussen, J. (2011). Linking badminton racket design and performance through motion capture. Computer Aided Medical Engineering, 2(1), 13-18.

Lees, A. (2002). Technique analysis in sports: A critical review. Journal of Sport Sciences, 20, 813-828.

Lei, R., Deng, S. X., \& Lu, L. F. (1993). Study on the physiological function, physical quality and mental characteristics of the Chinese badminton players. China Sport Science and Technology, 29, 28-38. 
Malina, R. M., Meleski, B. W., \& Shoup, R. F. (1982). Anthropometric, body composition, and maturity characteristics of selected school-age athletes. Pediatric Clinics of North America, 29(6), 1305-1323.

Malina, R. M. (2014). Top 10 research questions related to growth and maturation of relevance to physical activity, performance and fitness. Research Quarterly for Exercise and Sport, 85, 157-173.

Malina, R. M., Cumming, S. P., Rogol, A. D., Coelho-e-Silva, M. J., Figueiredo, A. J., Konarki, J. M., \& Koziel, S. M. (2019). Bio-banding in youth sports: Background, concept, and application. Sports Medicine, 49(11), 1671-1685.

Ming, C. L., Keong, C. C., \& Ghosh, A. K. (2008). Time motion and notational analysis of 21point and 15-point badminton match play. International Journal of Sport Science and Engineering, 2(4), 216-222.

Mirwald, R., Baxter-Jones, A., Bailey, D., \& Beunen, G. (2002). An assessment of maturity from anthropometric measurements. Medicine \& Science in Sports and Exercise, 34(4), 689694.

Mughal, H. A. (2019). Support at Work and its Relationship with Employee Performance: Critical Insights for Early Scholars. Annals of Contemporary Developments in Management \& HR (ACDMHR), 1(3), 16-21.

Newell, K. M. (1984). Physical constraints to development of motor skills. In Thomas, J.R. (ed.), Motor development during childhood and adolescence (pp. 105-120). Minneapolis, MN: Burgess.

Pandey, B. M., Reddy, O. T., \& Singh, V. (2019). Kinematical analysis of forehand overhead clear stroke at the time of contact phase in badminton. International Journal of Physiology, Nutrition and Physical Education, 4(1), 488-490.

Phomsoupha, M., \& Laffaye, G. (2014). Shuttlecock velocity during a smash stroke in badminton evolves linearly with skill level. Computational Methods in Biomechanics and Biomedical Engineering, 17, 140-141.

Phomsoupha, M., \& Laffaye, G. (2015). The science of badminton: Game characteristics, anthropometry, physiology, visual fitness and biomechanics. Sports Medicine, 45(4), 473-495.

Phomsoupha, M., \& Laffaye, G. (2020). A multiple repeated sprint ability test with four changes of direction for badminton players (part 2): predicting skill level with anthropometry, strength, shuttlecock and displacement velocity. Journal of Strength and Conditioning Research, 34(1), 203-211.

Quatman, C. E., Ford, K. R., Myer, G. D., \& Hewett, T. E. (2006). Maturation leads to gender differences in landing force and vertical jump performance. American Journal of Sports Medicine, 34(5).

Radnor, J. M., Oliver, J. L., Waugh, C. M., Myer, G. D., Moore, I. S., \& Lloyd, R. S. (2018). The influence of growth and maturation on stretch-shortening cycle function in youth. Sports Medicine, 48, 57-71.

Sigward, S. M., Pollard, C. D., \& Powers, C. M. (2011). The influence of sex and maturation on landing biomechanics: Implications for anterior cruciate ligament injury. Scandinavians Journal of Medicine \& Science in Sports, 22(4).

Sigward, S. M., Pollard, C. D., Havens, K. L., \& Powers, C. M. (2012). Influence of sex and maturation on knee mechanics during side-step cutting. Medicine \& Science in Sports \& Exercise, 44(8), 1497-1503. 
Sorensen, K., Zee, M. D., \& Rasmussen, J. (2011). A biomechanical analysis of clear strokes in badminton executed by youth players of different skill levels. International Society of Biomechanics (ISB) Congress, Brussels.

Tanner, J. M. (1978). Foetus into man: Physical growth from conception to maturity. Fletcher \& Son Ltd.. Norwich, Great Britain.

Viru, A., Loko, J., Harro, M., Volver, A., Laaneots, L., \& Viru, M. (1999). Critical Periods in the Development of Performance Capacity During Childhood and Adolescence. European Journal of Physical Education, 4(1), 75-119.

Zhu, Q. (2013). Expertise of using striking techniques for power stroke in badminton. Perceptual \& Motor Skills: Learning \& Memory, 117(2), 427-441. 